\section{Osteosarcoma metastasizing to pancreas confirmed by endoscopic ultrasound-guided fine-needle aspiration}

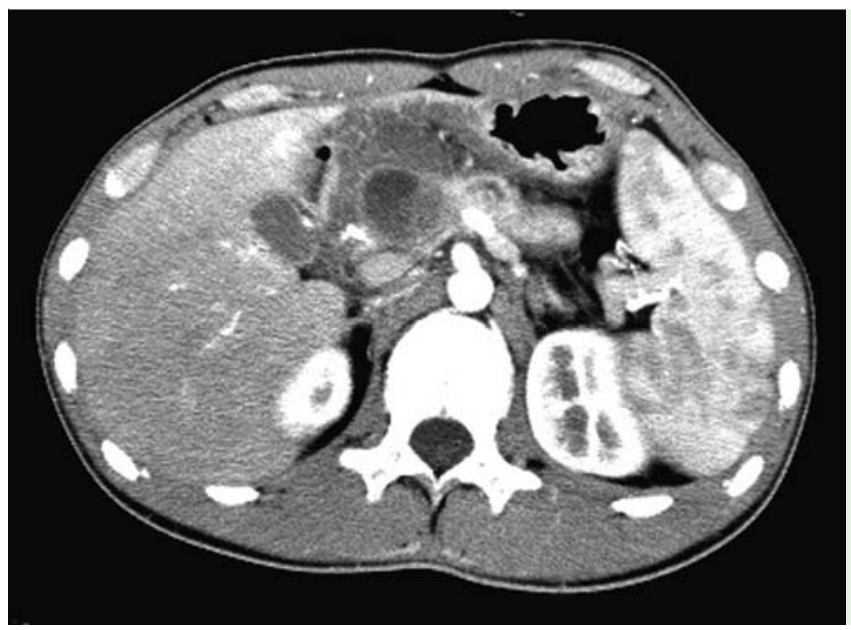

Fig. 1 Abdominal CT showed a cystic-solid mass on the head of the pancreas in an 18-yearold male patient.
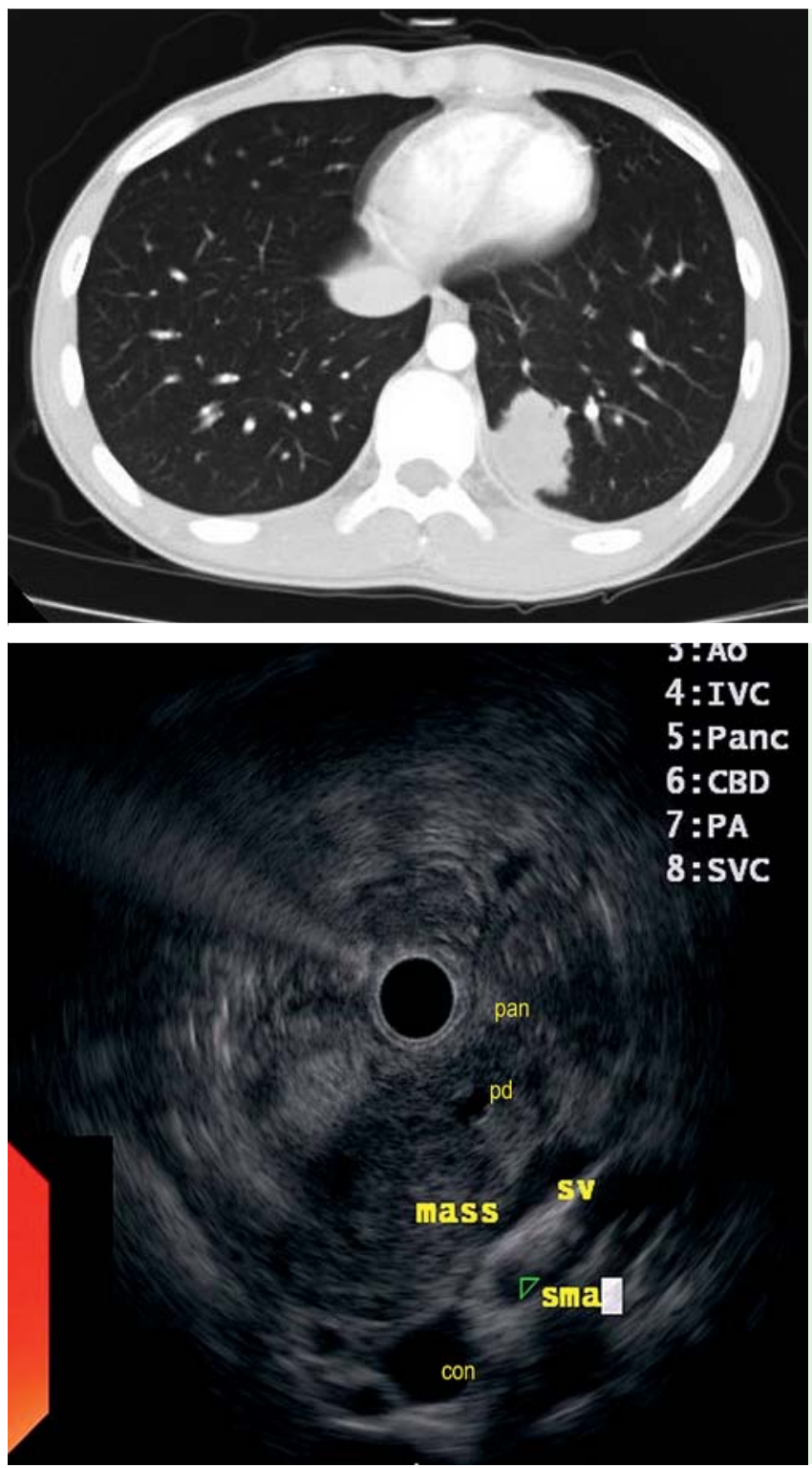

An 18-year-old male with a history of osteosarcoma of the proximal part of the left tibia presented complaining of upper abdominal pain and vomiting. Osteosarcoma had been diagnosed 4 years previously and been treated with amputation and chemotherapy. Laboratory tests revealed mild anemia (hemoglobin $114 \mathrm{~g} / \mathrm{L}$, reference range $120-150 \mathrm{~g} / \mathrm{L}$ ), and normal serum amylase and bilirubin. Abdominal computed tomography (CT) showed a cystic-solid mass measuring $4.3 \times 4.5 \mathrm{~cm}$ on the head of the pancreas ( Fig. 1 ). Thoracic CT revealed another mass in the inferior lobe of the left lung ( $\bullet$ Fig.2). No calcification was seen in either lesion. Endoscopic ultrasound (EUS) was carried out using an electronic echoendoscope (GF-UE260-AL5 for radial scanning and GF-UCT240-AL5 for linear scanning; Olympus, Tokyo, Japan) and this showed more clearly a mass containing necrotic areas in the pancreatic head and neck and a dilated pancreatic duct ( $\mathrm{Fig.3}$ and Fig.4). Endoscopic ultrasoundguided fine-needle aspiration (EUS-FNA) of the pancreatic mass using a 22-gauge needle (EchoTip Ultra; Cook Medical Inc., Winston-Salem, NC, USA) confirmed the diagnosis of metastatic osteosarcoma ( Fig.5 and Fig.6). Pancreatoduodenectomy and thoracotomy with resection of the left inferior lobe was then performed, followed by chemotherapy. At 7 months postoperatively the patient had recovered from the treatment and remained free of detectable disease.

Osteosarcoma possesses a high potential for metastasis. The most common sites of metastatic osteosarcoma are the lung, pleurae, and bone. Metastasis to the pancreas is extremely rare [1], and pulmonary metastases usually occur before pancreatic metastases [2]. Our case demonstrates that EUS-FNA is a useful method for definitive diagnosis of pancreatic metastasis in a patient with a history of extrapancreatic malignancy.

Endoscopy_UCTN_Code_CCL_1AF_2AZ

Competing interests: None 

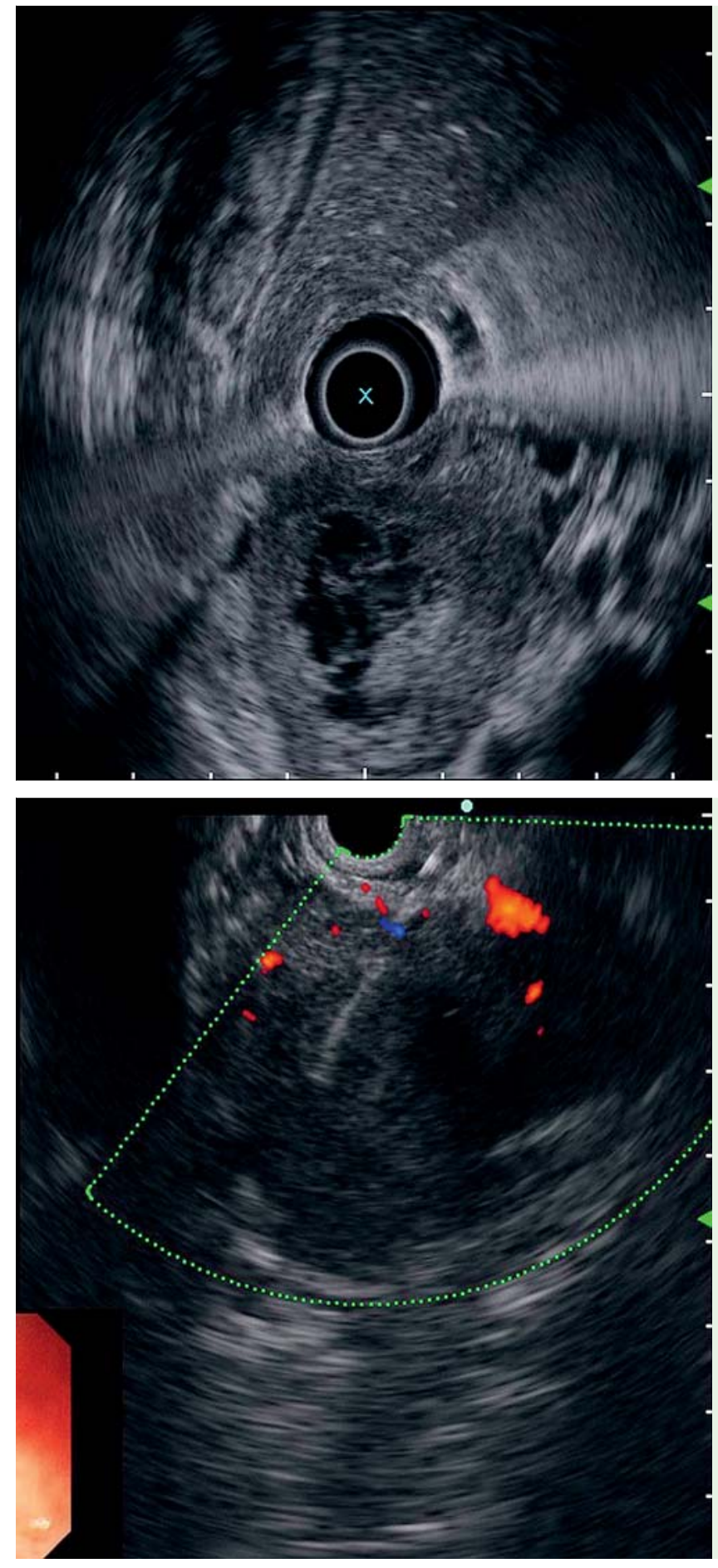

Fig.4 Endoscopic ultrasound clearly showed the pancreatic mass containing necrotic areas.

Fig. 5 Endoscopic ultrasound-guided fine-needle aspiration of the pancreatic mass with a 22-gauge needle.

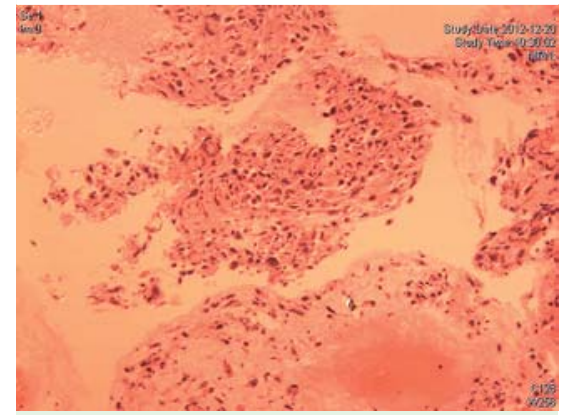

Fig. 6 Histopathologic analysis revealed amorphous pink-colored osteoid structures with pleomorphic multinucleated sarcomatoid cells.

\section{Peng Jin ${ }^{1,2}$, Wei Wang ${ }^{3}$, Hui Su', Jian-qiu Sheng ${ }^{1}$}

${ }^{1}$ Department of Gastroenterology, Beijing Military General Hospital, Beijing 100700 , P. R. China

2 Third Military Medical University, Chongqing 400038, P. R. China

${ }^{3}$ Department of Radiology, Beijing Military General Hospital, Beijing 100700,

\section{P. R. China}

\section{References}

1 Avcu S, Akdeniz H, Arslan $H$ et al. A case of primary vertebral osteosarcoma metastasizing to pancreas. J Pancreas (Online) 2009; 10: $438-440$

2 Aarvold A, Bann S, Giblin V et al. Osteosarcoma metastasising to the duodenum and pancreas. J Bone Joint Surg [Br] 2007; 89: $542-544$

\section{Bibliography}

Dol http://dx.doi.org/

10.1055/s-0033-1359238

Endoscopy 2014; 46: E109-E110

(c) Georg Thieme Verlag KG

Stuttgart · New York

ISSN 0013-726X

\section{Corresponding author}

Jian-qiu Sheng, MD

Department of Gastroenterology

Beijing Military General Hospital

Nanmencang 5\#

Dongcheng District

Beijing 100700

People's Republic of China

jianqiu@263.net 